handbook.pubpub.org

\title{
Visualizing Objects, Places, and Spaces: A Digital Project Handbook
}

Beth Fischer (Williams College Museum of Art) \& Hannah L. Jacobs (Duke University), Co-Editors

\section{Introduction}

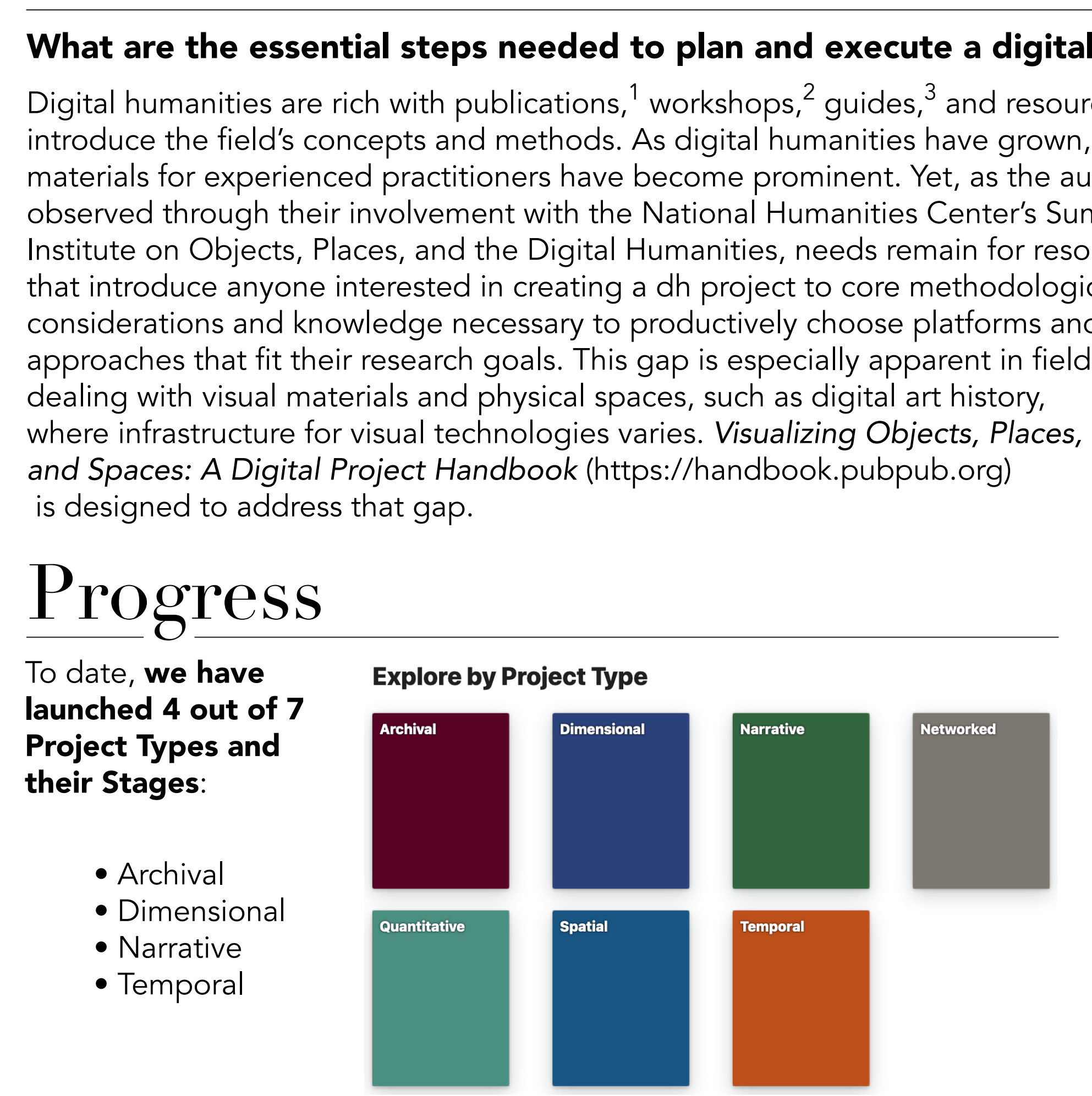

Each of these sections was written by the project's co-editors and reviewed by multiple colleagues from a range of disciplines and with varying experiences in digital We are in the process of launching the first 14 Assignments and 28 Case Studies. Each of these submissions offers practical information and insight from current and past digital humanities projects.

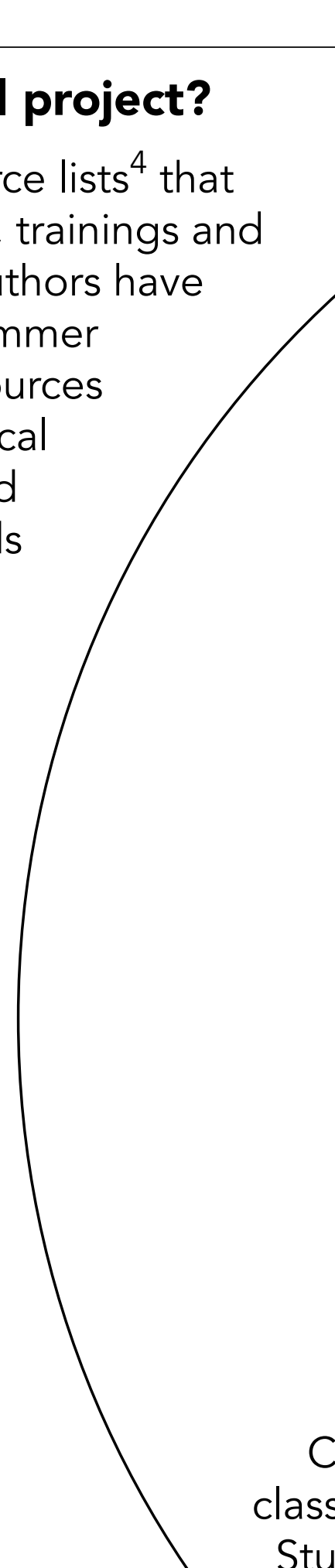

Connected to each Project Type are a series of research Case Studies and Contributed by colleagues from around the world. Case Studies and Assignments offer information about why and how projects were formed and the tools, expertise, and resources needed to create them. o kubub (pubpub.org), the Handbor Types cover information specific to a particular method. Stages cover a range of topics specific to each project type.
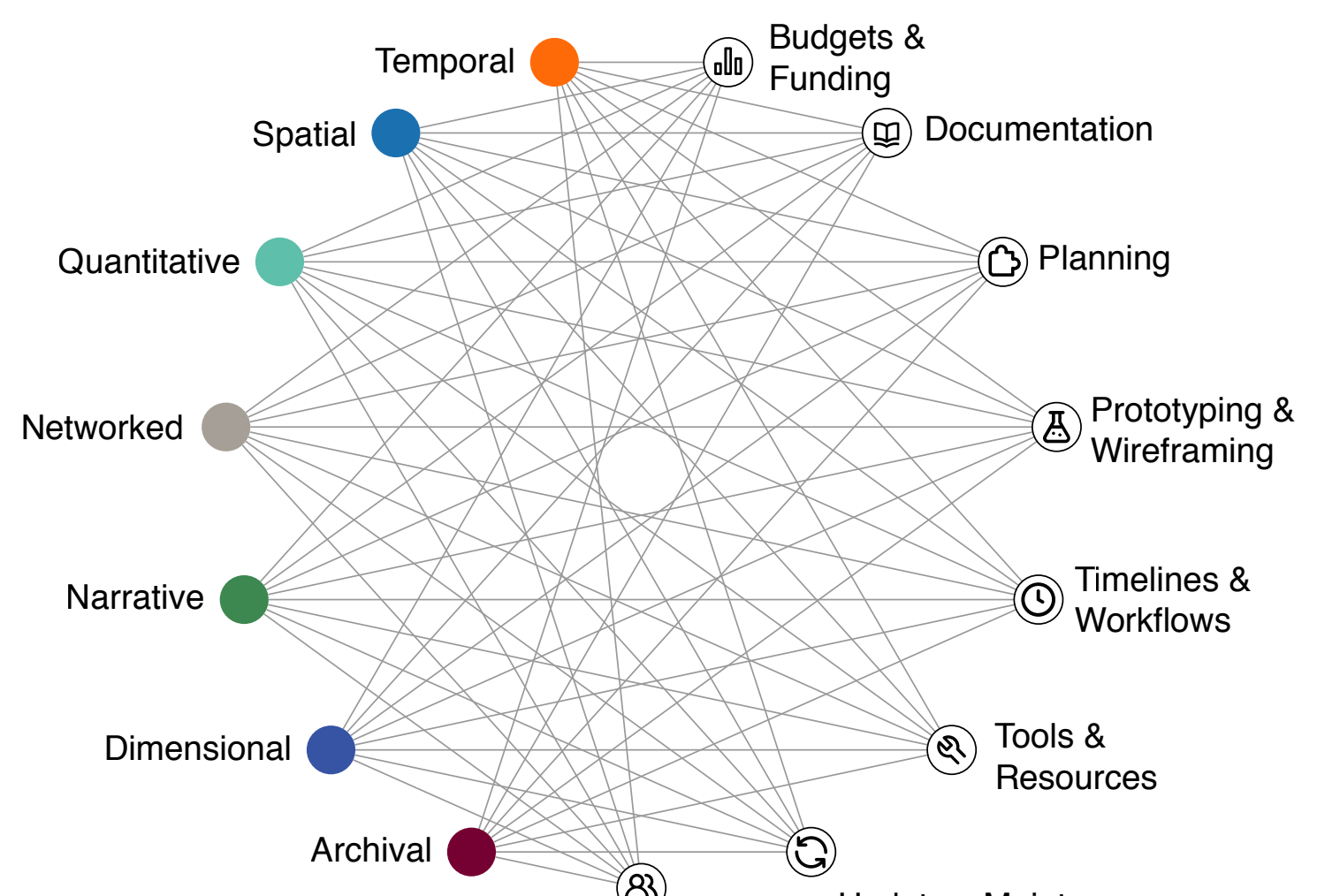

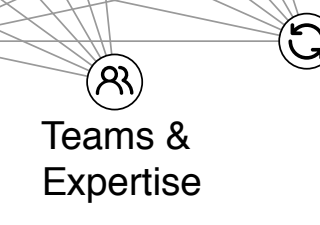
Updates, Maintenance,
Sustainability
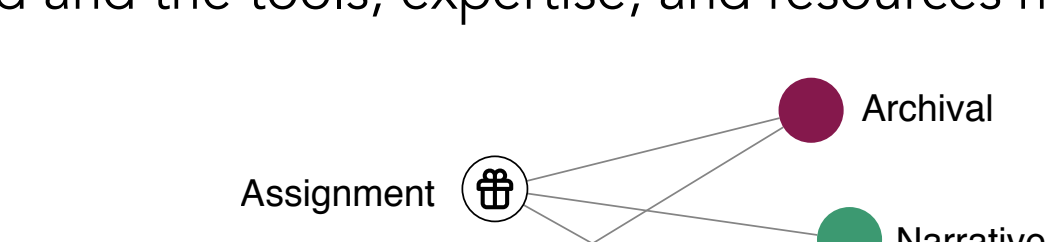

Case Study $(\Delta)$
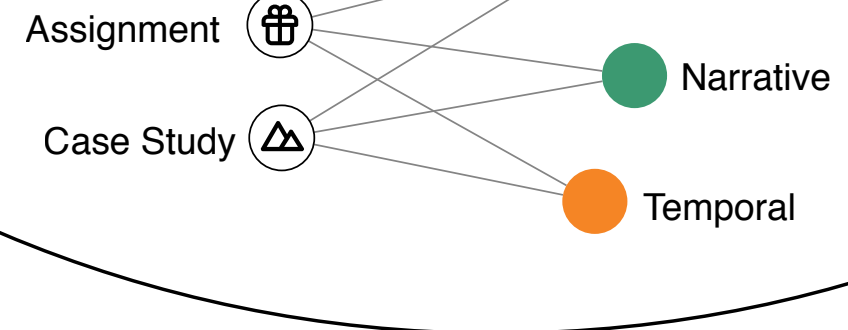

In the coming months, we'll be launching the 3 remaining Project Types: - Networked - Quantitative

We'll also be posting a new call for Assignments and Case Studies Explore by Project Stage other Project Types.

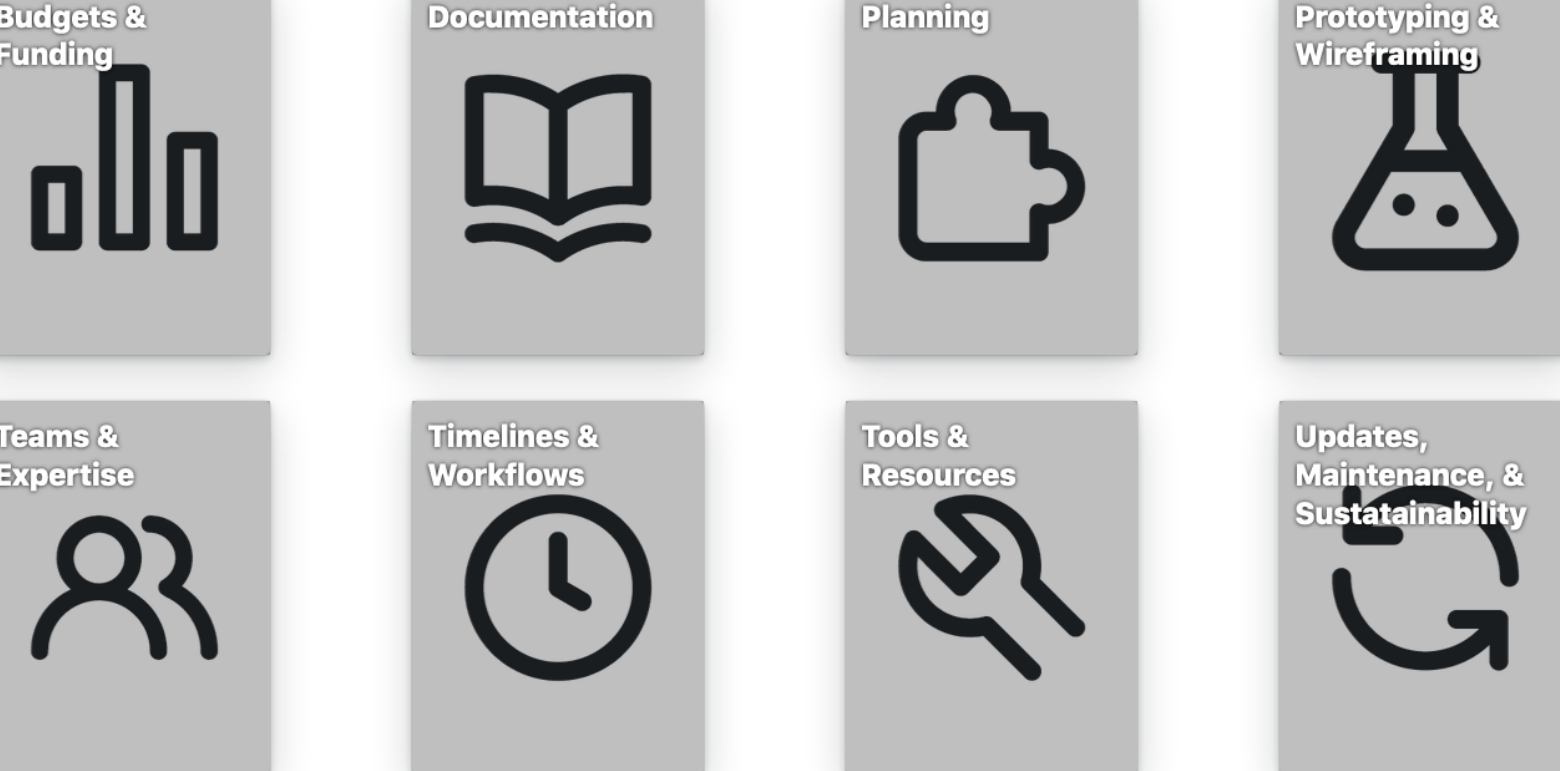

Get Involved

\section{- Become a reviewer for our project} stages and types. Submit an assignment or case study. - Send us feedback What kinds of information are missing? How are you using the handbook?

digitalhandbookeduke.edu. Find out more at handbook.pubpub.org 